\title{
Comparison of Biotin Interference in Second- and Third-Generation Roche Free Thyroxine Immunoassays
}

\author{
Jungim Choi $\mathbb{C}^{-}$, M.D. and Seung Gyu Yun $\mathbb{C}^{\circ}$, M.D., Ph.D. \\ Department of Laboratory Medicine, College of Medicine Korea University, Seoul, Korea
}

\section{Dear Editor,}

Immunoassays (IAs) based on streptavidin-biotin binding are widely used in clinical laboratory testing owing to the high affinity and stable interaction between streptavidin and biotin (vitamin B7) and the development of various biotinylation methods [1]. Biotin is a water-soluble B-complex vitamin and a coenzyme responsible for carboxyl transfer in essential carboxylases. Circulating serum concentrations of biotin in the general population typically range from $0.1 \mathrm{ng} / \mathrm{mL}$ to $0.8 \mathrm{ng} / \mathrm{mL}$ [2]. Biotin is rapidly absorbed, reaches peak plasma concentrations within 1-2 hours, and has an effective serum half-life of 15 hours [3]. Oral administration of biotin doses of $10 \mathrm{mg}$ resulted in peak plasma concentrations ranging from $53 \mathrm{ng} / \mathrm{mL}$ to $141 \mathrm{ng} / \mathrm{mL}[3$, 4]. Considering a maximum dosage of $10 \mathrm{mg}$ once a day (q.d.; $10 \mathrm{mg}$ is $>300$-fold the adequate daily intake) via over the counter (OTC) biotin products, the serum biotin concentration would drop below the in vitro interference threshold of $\leq 30 \mathrm{ng} / \mathrm{mL}$ after eight hours [3]. A high biotin concentration in the blood can interfere with IAs based on streptavidin-biotin binding and is known to cause false high results in competitive IAs and false low results in sandwich IAs [1]. Although the recommended daily intake of biotin is low (30 $\mathrm{\mu g} / \mathrm{day})$, the use of high-dose biotin supplements (up to $10 \mathrm{mg}$ ), which are available OTC, has increased in recent years due to unfounded claims that biotin exerts beneficial effects on hair, nails, and skin [5]. According to one survey, $7.7 \%$ (95\% confidence interval [Cl], 6.6-8.9\%) of an outpatient population $(\mathrm{N}=1,944)$ indicated biotin use; measuring biotin in plasma samples from emergency department patients $(\mathrm{N}=1,442)$ showed that $7.4 \%(95 \% \mathrm{Cl}, 6.2-8.9 \%)$ had a concentration at or above the lowest known threshold (10 ng/ $\mathrm{mL}$ ) for biotin interference in a Roche Diagnostics IA (Indianapolis, IN, USA) [6].

Because the Roche Elecsys assay is based on streptavidin-biotin binding, it may yield incorrect results for samples with high biotin concentration. Measurement of free thyroxine (FT4) using a competitive IA from Roche Diagnostics revealed that high biotin concentrations led to false high results in the Elecsys FT4 II assay. Recently, Roche Diagnostics released the Elecsys FT4 III assay, which is claimed to perform better in the presence of biotin interference. This is the first study to evaluate biotin interference in FT4 assays by comparing the newly released Elecsys FT4 III assay with the previous Elecsys FT4 II assay using a Cobas e602 Analyzer (Roche Diagnostics). The Institutional Review Board of Korea University Anam Hospital, Seoul, Korea, approved this study and waived the need for informed consent (No. 2019AN0400).

Pooled serum samples from 10 subjects with three targeted FT4 concentrations (high: $>3 \mathrm{ng} / \mathrm{dL}$; normal: $0.89-1.8 \mathrm{ng} / \mathrm{dL}$; low: $<0.8 \mathrm{ng} / \mathrm{dL}$ ) were prepared by mixing three or four serum samples remaining after routine clinical assays of T3 and FT4.
Received: July 24, 2019

Revision received: September 25, 2019

Accepted: November 22, 2019

Corresponding author: Seung Gyu Yun, M.D., Ph.D.

Department of Laboratory Medicine, Anam Hospital of Korea University,

73 Goryeodae-ro, Seongbuk-gu, Seoul 02841, Korea

Tel: +82-2-920-5905; Fax: +82-2-920-5538

E-mail: koryun@korea.ac.kr

\section{(c) (1) $(9$}

\section{(C) Korean Society for Laboratory Medicine}

This is an Open Access article distributed under the terms of the Creative Commons Attribution Non-Commercial License (http://creativecommons.org/licenses/by-nc/4.0) which permits unrestricted non-commercial use, distribution, and reproduction in any medium, provided the original work is properly cited. 
Table 1. Comparison of relative bias in biotin concentration between Elecsys FT4 II and Elecsys FT4 III

\begin{tabular}{|c|c|c|c|c|c|c|c|c|c|c|c|c|}
\hline \multirow{3}{*}{$\begin{array}{l}\text { Estimated } \\
\text { biotin } \\
\text { concentration } \\
(\mathrm{ng} / \mathrm{mL})\end{array}$} & \multicolumn{6}{|c|}{ Elecsys FT4 II } & \multicolumn{6}{|c|}{ Elecsys FT4 III } \\
\hline & \multicolumn{2}{|c|}{ Low FT4 } & \multicolumn{2}{|c|}{ Normal FT4 } & \multicolumn{2}{|c|}{ High FT4 } & \multicolumn{2}{|c|}{ Low FT4 } & \multicolumn{2}{|c|}{ Normal FT4 } & \multicolumn{2}{|c|}{ High FT4 } \\
\hline & $\begin{array}{c}\mathrm{FT} 4 \\
\text { (ng/dL) }\end{array}$ & $\begin{array}{l}\text { Relative } \\
\text { bias (\%) }\end{array}$ & $\begin{array}{c}\mathrm{FT} 4 \\
\text { (ng/dL) }\end{array}$ & $\begin{array}{l}\text { Relative } \\
\text { bias (\%) }\end{array}$ & $\begin{array}{c}\mathrm{FT} 4 \\
\text { (ng/dL) }\end{array}$ & $\begin{array}{l}\text { Relative } \\
\text { bias (\%) }\end{array}$ & $\begin{array}{c}\text { FT4 } \\
\text { (ng/dL) }\end{array}$ & $\begin{array}{l}\text { Relative } \\
\text { bias (\%) }\end{array}$ & $\begin{array}{c}\mathrm{FT} 4 \\
\text { (ng/dL) }\end{array}$ & $\begin{array}{l}\text { Relative } \\
\text { bias (\%) }\end{array}$ & $\begin{array}{c}\mathrm{FT} 4 \\
\text { (ng/dL) }\end{array}$ & $\begin{array}{l}\text { Relative } \\
\text { bias (\%) }\end{array}$ \\
\hline 0 & 0.76 & 0.0 & 1.34 & 0.0 & 5.05 & 0.0 & 0.72 & 0.0 & 1.27 & 0.0 & 4.62 & 0.0 \\
\hline 12.5 & 0.81 & 6.0 & 1.38 & 3.0 & 5.24 & 3.8 & 0.68 & -5.6 & 1.21 & -4.7 & 4.40 & -4.8 \\
\hline 25 & 0.82 & 6.7 & 1.42 & 6.0 & 5.43 & 7.4 & 0.68 & -5.0 & 1.19 & -5.9 & 4.44 & -3.9 \\
\hline 50 & 0.86 & 12.2 & 1.47 & 9.7 & 5.79 & 14.6 & 0.66 & -8.4 & 1.17 & -7.9 & 4.42 & -4.4 \\
\hline 100 & 0.93 & 21.6 & 1.60 & 19.9 & 6.46 & 27.8 & 0.67 & -6.8 & 1.17 & -7.5 & 4.69 & 1.5 \\
\hline 200 & 1.08 & 40.6 & 1.82 & 36.0 & $>7.77$ & $>53.9$ & 0.74 & 3.2 & 1.34 & 5.9 & 6.43 & 39.2 \\
\hline 400 & 2.39 & 212.0 & 3.91 & 192.5 & $>7.77$ & $>53.9$ & 0.95 & 32.5 & 1.62 & 27.7 & 6.65 & 43.8 \\
\hline
\end{tabular}

Relative biases $>10 \%$ are in bold.

Abbreviation: FT4, free thyroxine.

Biotin was purchased from Sigma-Aldrich (St. Louis, MO, USA) to produce a stock solution $(4,000 \mathrm{ng} / \mathrm{mL})$ for spiking the pooled serum samples (4 mL for each level). High-, normal-, and lowconcentration samples were mixed with the biotin stock solution (9:1, high-biotin pool). For each FT4 range sample, the zeroand high-biotin serum pools were serially diluted to produce biotin-spiked samples (biotin concentration, 12.5, 25, 50, 100, 200 , and $400 \mathrm{ng} / \mathrm{mL}$ ). For both FT4 assays, all samples were analyzed in duplicate using a Roche Cobas e602 Analyzer. All experiments were completed in less than eight hrs without storage. Relative bias was calculated as follows:

bias $(\%)=([$ biotin-treated analyte] $-[$ untreated analyte] $\gamma$ [untreated analyte]).

To determine the biotin interference concentration, a clinically significant bias was defined as a $10 \%$ change in the result. For the Elecsys FT4 II assay, a biotin concentration $\geq 50 \mathrm{ng} / \mathrm{mL}$ caused a positive bias in low- and high-concentration pooled samples, while the normal-concentration samples showed $>10 \%$ bias starting at $100 \mathrm{ng} / \mathrm{mL}$ of biotin. For Elecsys FT4 III, low- and normal-concentration pooled samples showed a positive bias of $32.5 \%$ and $27.7 \%$ at $400 \mathrm{ng} / \mathrm{mL}$, respectively. For the high-concentration samples, a positive bias of $39.2 \%$ and $43.8 \%$ was observed at biotin concentrations of 200 and $400 \mathrm{ng} / \mathrm{mL}$, respectively. The Elecsys FT4 II data sheet indicates a biotin interference threshold of $\leq 25 \mathrm{ng} / \mathrm{mL}$. Thus, our findings showed that Elecsys FT4 III is less sensitive to biotin interference and corroborate its revised biotin interference threshold $(\leq 100 \mathrm{ng} / \mathrm{mL}$ ) (Table 1).

In conclusion, Elecsys FT4 III showed decreased biotin interference compared with the previous version of the assay, but an appreciable number of false results were noted. Therefore, labo- ratories, clinicians, and patients should be aware of the potential for biotin interference in IAs based on streptavidin-biotin binding and take measures to minimize the risk of false results. If biotin interference is suspected, additional methods can be used to reduce the risk of false results, including analysis with an alternative assay that is not based on biotin, use of a sample diluent, or removal of excess biotin using streptavidin-coated beads [7, 8]. Furthermore, based on population pharmacokinetics of exogenous biotin, we recommend that samples from patients receiving therapy with high doses of biotin (i.e., $>5 \mathrm{mg} /$ day) should be assayed at least eight hrs following final biotin administration $[3,4,8]$.

\section{ACKNOWLEDGEMENTS}

None declared.

\section{AUTHOR CONTRIBUTIONS}

SGY designed the study. JC and SGY contributed to the implementation of the research, analysis of the results, and writing of the manuscript.

\section{CONFLICTS OF INTEREST}

None declared.

\section{RESEARCH FUNDING}

None declared. 


\section{ORCID}

Jungim Choi https://orcid.org/0000-0001-9598-453X

Seung Gyu Yun https://orcid.org/0000-0002-9915-9681

\section{REFERENCES}

1. Piketty ML, Polak M, Flechtner I, Gonzales-Briceño L, Souberbielle JC. False biochemical diagnosis of hyperthyroidism in streptavidin-biotinbased immunoassays: the problem of biotin intake and related interferences. Clin Chem Lab Med 2017;55:780-8.

2. Livaniou E, Evangelatos GP, Ithakissios DS, Yatzidis H, Koutsicos DC. Serum biotin levels in patients undergoing chronic hemodialysis. Nephron 1987;46:331-2.

3. Grimsey P, Frey N, Bendig G, Zitzler J, Lorenz O, Kasapic D, et al. Population pharmacokinetics of exogenous biotin and the relationship between biotin serum levels and in vitro immunoassay interference. Int J
Pharmacokinet 2017;2:247-56

4. Peyro Saint Paul L, Debruyne D, Bernard D, Mock DM, Defer GL. Pharmacokinetics and pharmacodynamics of MD1003 (high-dose biotin) in the treatment of progressive multiple sclerosis. Expert Opin Drug Metab Toxicol 2016;12:327-44.

5. Lipner SR. Rethinking biotin therapy for hair, nail, and skin disorders. J Am Acad Dermatol 2018;78:1236-8.

6. Katzman BM, Lueke AJ, Donato LJ, Jaffe AS, Baumann NA. Prevalence of biotin supplement usage in outpatients and plasma biotin concentrations in patients presenting to the emergency department. Clin Biochem 2018;60:11-6.

7. Gifford JL, Sadrzadeh SMH, Naugler C. Biotin interference: underrecognized patient safety risk in laboratory testing. Can Fam Physician 2018;64:370.

8. Trambas C, Lu Z, Yen T, Sikaris K. Depletion of biotin using streptavidincoated microparticles: a validated solution to the problem of biotin interference in streptavidin-biotin immunoassays. Ann Clin Biochem 2018; 55:216-26 